\title{
ANALISIS FAKTOR PEMILIHAN LOKASI USAHA PEDAGANG IKAN ASAP DI SEKITAR PANTAI KENJERAN, KECAMATAN BULAK
}

\section{FACTOR ANALYSIS IN SELECTION OF BUSINESS LOCATION FOR SMOKED FISH SELLERS AROUND THE KENJERAN BEACH, BULAK DISTRICT}

\section{NINDY FADILLAH*, SRI TJONDRO WINARNO, HAMIDAH HENDRARINI}

Fakultas Pertanian, Universitas Pembangunan Nasional "Veteran" Jawa Timur, Surabaya

*E-mail : nindyf.agb17@gmail.com

\begin{abstract}
ABSTRAK
Sentra Ikan Bulak (SIB) adalah fasilitas yang diberikan oleh Pemerintah Kota Surabaya guna memfasilitasi pemasaran hasil olahan laut yang ada di Kecamatan Bulak. Akan tetapi, minat pedagang untuk menempati SIB masih rendah, khususnya pedagang ikan asap. Tujuan dari penelitian ini untuk menganalisis faktor yang paling dominan dalam pemilihan lokasi usaha di sekitar jalan Pantai Kenjeran, Kecamatan Bulak, Kota Surabaya. Pengumpulan data dilakukan dengan observasi, wawancara, dokumentasi dan dianalisis dengan analisis faktor. Hasil penelitian menunjukkan bahwa terdapat 2 faktor yang paling dominan dalam pemilihan lokasi usaha yaitu: (1) Aksesibilitas dan fasilitas, (2) lalu lintas. Faktor yang paling dominan dalam pemilihan lokasi usaha bagi pedagang ikan asap di sekitar jalan Pantai Kenjeran adalah aksesibilitas dan fasilitas (47,416\%).
\end{abstract}

Kata Kunci : analisis faktor, lokasi, pedagang ikan asap.

\section{ABSTRACT}

Sentra Ikan Bulak (SIB) is a facility provided by the Surabaya City Government to facilitate the marketing of marine processed products in Bulak District. However, the interest of traders to occupy SIB is still low, especially smoked fish sellers. This research aims to analyze the most dominant factors in the selection of business locations around the Kenjeran Beach road, Bulak District, Surabaya City. Data collection was done by observation, interview, documentation and analyzed by factor analysis. The results showed that there were 2 factors that were most dominant in choosing a business location, namely: (1) Accessibility and facilities, (2) traffic. The most dominant factor in selection of business location for smoked fish sellers around the Kenjeran Beach road is accessibility and facilities (47.416\%).

Keywords : factor analysis, place factor, smoked fish sellers.

\section{PENDAHULUAN}

Pemasaran merupakan cara
perusahaan yang diawali dengan
identifikasi kebutuhan dan keinginan
konsumen, menentukan produk yang akan
dijual, harga, promosi, dan distribusi
produk (Mawardi, 2021). Pada bauran
pemasaran terdapat 7 aspek, yaitu product
(produk), price (harga), place (tempat), dan

promotion (promosi), people (orangorang), physical evidence (bukti fisik), dan process (proses) (Kotler and Amstrong, 2016). Lokasi usaha adalah tempat bagi suatu usaha beroperasi. Keputusan lokasi dapat mempengaruhi proses optimasi yang melibatkan memaksimalkan keuntungan atau meminimalkan biaya. Jarak, lokasi bersama 
(spesialisasi) dan ukuran perusahaan memiliki kaitan dengan keputusan lokasi (Dubé, Brunelle, and Legros, 2016). Lokasi perusahaan dapat menentukan efisiensi dan efektifitas perusahaan dalam jangka panjang (Haming, 2011). Tinggi rendah biaya operasional, harga maupun kemampuan bersaing berkaitan dengan pemilihan lokasi sehingga sangat penting bagi perusahaan. Lokasi mengacu pada aktivitas pemasaran untuk memperlancar dan mempermudah distribusi barang dan jasa (Tjiptono, 2015). Lokasi menjadi faktor penting dalam pengembangan usaha karena lokasi usaha bagi pedagang eceran merupakan penentu utama pendapatan (Heizer and Render, 2012). Faktor lokasi dan faktor kualitas pelayanan mempengaruhi kepuasan pelanggan. Lokasi dan kualitas pelayanan akan meningkatkan keberhasilan usaha, pencapaian target, serta profitabilitas (In seok, Gyu yeon, and Sang Bong, 2016).

Pemilihan lokasi usaha merupakan salah satu faktor yang harus dipertimbangkan oleh seorang pengusaha dalam strategi bisnis karena dapat mempengaruhi keberhasilan dari usaha tersebut (Wahyudi, Lau, and Heriyanto, 2014). Menurut Alcácer (2006), walaupun jarak dengan pesaing berdekatan, pemilik usaha dapat bersaing melalui harga atau produk yang ditawarkan. Seorang pengusaha harus mengenali jumlah dan ukuran bisnis lain serta situasi persaingan yang ada di daerah tersebut. Terdapat beberapa faktor yang harus diperhatikan dalam melakukan pemilihan lokasi, antara lain : aksesibilitas, visitabilitas, lalu lintas, tempat parkir, lingkungan, ekspansi,

Kota Surabaya adalah salah satu kota yang memiliki garis pantai sepanjang 47,4 $\mathrm{Km}^{2}$ dengan luas daratan wilayah Kota Surabaya sebesar $33.048 \mathrm{Ha}$ dan Luas wilayah laut yang masuk dalam wilayah administrasi oleh Kota Surabaya sebesar 19.039 Ha. Produksi perikanan tangkap di Kota Surabaya berasal dari laut dan perairan umum. Pada Tahun 2020, hasil penangkapan laut mencapai 7.592,5 Ton (Dinas Pertanian Kota Surabaya, 2020).

Usaha perikanan tangkap di Kota Surabaya tidak hanya meliputi penangkapan ikan dan budidaya ikan saja, melainkan juga usaha pasca penangkapan yaitu pemasaran dan pengolahan yang umumnya masih berskala rumah tangga. Salah satu sentra olahan ikan di Kota Surabaya adalah Kecamatan Bulak. Olahan hasil laut yang terdapat di Kecamatan Bulak terdiri dari ikan kering, gragu, olahan kerang, ikan panggangan (ikan asap), bakso ikan, abon ikan, dan kerupuk hasil laut. 
Sentra Ikan Bulak (SIB) adalah fasilitas yang diberikan oleh Pemerintah Kota Surabaya guna memfasilitasi pemasaran hasil olahan laut yang ada di Kecamatan Bulak. Akan tetapi, bangunan yang telah berdiri sejak Tahun 2012 ini masih saja kurang diminati oleh para pedagang, khususnya pedagang ikan asap. Pedagang ikan asap memilih untuk berjualan di jalanan sekitar Pantai Kenjeran dengan menyewa kios, berjualan di depan rumah, ataupun berjualan di pinggir jalan.

Berdasarkan penelitian Nanda and Fikriah (2016) pada Pedagang Kaki Lima (PKL) di Kota Banda Aceh, faktor-faktor yang mempengaruhi pemilihan lokasi Pedagang Kaki Lima (PKL) adalah kedekatan lokasi dengan tempat keramaian dan kedekatan lokasi dengan tempat tinggal. Hal ini didukung oleh penelitian Sastrawan (2015) di Pantai Penimbangan Kecamatan Buleleng, terdapat 8 faktor yang mempengaruhi pemilihan lokasi Pedagang Kaki Lima (PKL) yaitu aksesibilitas, visibilitas, lalulintas (traffic), tempat parkir, ekspansi, lingkungan, persaingan, peraturan pemerintah dengan faktor yang paling dominan adalah aksesibilitas.

Tujuan dari penelitian ini untuk menganalisis faktor - faktor yang memengaruhi pemilihan lokasi usaha pedagang ikan asap di sekitar jalan Pantai Kenjeran, Kecamatan Bulak, Kota Surabaya serta menganalisis faktor yang paling dominan dalam pemilihan lokasi usaha di sekitar jalan Pantai Kenjeran, Kecamatan Bulak, Kota Surabaya.

\section{METODE PENELITIAN}

Penelitian ini dilaksanakan pada bulan April 2021 di Kecamatan Bulak, Kota Surabaya. Objek dalam penelitian ini yaitu faktor pemilihan lokasi usaha pedagang ikan asap di sekitar jalan Pantai Kenjeran. Metode penentuan lokasi dan objek penelitian dilakukan secara sengaja (purposive method), dengan pertimbangan banyaknya pedagang yang memilih berjualan di sekitar jalan Pantai Kenjeran dibanding menghuni Sentra Ikan Bulak (SIB).

Populasi pada penelitian ini adalah seluruh pedagang ikan asap di Kecamatan Bulak meliputi pedagang yang menghuni Sentra Ikan Bulak (SIB) serta yang berjualan di tempat lain sejumlah 29 orang. Pengambilan sampel pada penelitian ini dilakukan dengan metode purposive sampling yaitu penentuan sampel dengan kriteria tertentu yang telah dipertimbangkan oleh peneliti (Etikan, Musa, and Alkassim, 2016). Kriteria sampel pada penelitian ini adalah pedagang yang berjualan di sekitar 
jalan Pantai Kenjeran, Kecamatan Bulak sejumlah 21 orang pedagang ikan asap.

Penelitian ini menggunakan data primer dan sekunder yang dikumpulkan melalui observasi, wawancara, serta dokumentasi. Data primer meliputi data karakteristik pedagang ikan asap dan faktor pemilihan lokasi usaha pedagang ikan asap di sekitar Pantai Kenjeran. Data sekunder meliputi artikel mengenai pedagang ikan asap di sekitar Pantai Kenjeran dan Sentra Ikan Bulak (SIB) dan kondisi sosial ekonomi masyarakat sekitar.

Data yang telah diperoleh dianalisis dengan metode analisis faktor untuk mengetahui faktor - faktor yang memengaruhi dan faktor yang paling dominan pemilihan lokasi usaha pedagang ikan asap di sekitar jalan Pantai Kenjeran. Analisis faktor digunakan untuk mengurangi dan meringkas data tanpa kehilangan informasi penting atau mereduksi data dari variabel yang banyak diubah menjadi variabel yang lebih sedikit jumlahnya (Supranto, 2010).

Menurut (Williams and Brown, 2012) analisis faktor memiliki lima langkah antara lain :

1. Data layak/dapat dianalisis dengan analisis faktor jika nilai KMO MSA (Kaiser Mayer Olkin Measure of Sampling Adequancy) $>5$.
2. Menentukan ketepatan model dengan melihat jumlah residual antar korelasi yang diamati dengan korelasi yang diproduksi.

3. Kriteria penentuan ekstraksi faktor. Ekstraksi data bertujuan untuk mereduksi sejumlah besar item menjadi faktor.

4. Rotasi faktor. Dengan menggunakan rotasi faktor matriks, matriks faktor akan ditransformasikan kedalam matriks yang lebih sederhana sehingga mudah untuk diinterpretasikan.

5. Interpretasi faktor, dilakukan dengan mengelompokkan variabel yang mempunyai faktor loading tinggi kedalam faktor tersebut.

Variabel digunakan dalam penelitian ini antara lain aksesibilitas, visitabilitas, lalu lintas, fasilitas, dan biaya. Definisi operasional penelitian ini adalah:

1. Lokasi usaha adalah tempat dilakukannya kegiatan yang berhubungan dengan produksi dan penjualan ikan asap. Cara penentuan lokasi usaha dapat dilakukan dengan mempertimbangkan faktor - faktor pemilihan lokasi usaha.

2. Aksesibilitas adalah pengukuran kemudahan dari lokasi usaha ikan asap sehingga dapat dijangkau. 
Adapat dilihat dari kemudahan waktu, biaya, serta usaha perpindahan atau pergerakan antar tempat.

3. Visibilitas adalah pengukuran kemudahan dari suatu lokasi usaha ikan asap sehingga dapat dilihat dan diamati dengan jelas.

4. Lalu lintas (traffic) adalah tingkat lalu lalang yang terjadi di sekitar pantai Kenjeran, Kecamatan Bulak, Kota Surabaya. Pengukuran lalu lintas pada penelitian ini menyangkut banyaknya orang yang berlalu lalang serta kemacetan dan kepadatan jalan.

5. Fasilitas adalah sarana yang mendukung atau memperlancar operasional pedagang ikan asap.

6. Biaya adalah sejumlah uang yang dikeluarkan oleh pedagang ataupun pembeli ikan asap.

Indikator pada setiap variabel dapat dilihat pada Tabel 1.

Tabel 1. Indikator Penelitian

\begin{tabular}{ll}
\hline \multicolumn{1}{c}{ Variabel } & \multicolumn{1}{c}{ Indikator } \\
\hline Aksesibilitas & $\begin{array}{l}\text { A1 (Kemudahan keluar } \\
\text { masuk jalan raya) }\end{array}$ \\
\cline { 2 - 2 } & $\begin{array}{l}\text { A2 (dilalui transportasi } \\
\text { umum) }\end{array}$ \\
\cline { 2 - 2 } & A3 (mudah dijangkau) \\
\hline Visitabilitas & V1 (dekat dengan jalan raya) \\
\cline { 2 - 2 } Lalu Lintas & $\begin{array}{l}\text { VL1 (terdapat penanda) } \\
\text { yang melintas) }\end{array}$ \\
\cline { 2 - 2 } & $\begin{array}{l}\text { LL2 (kendaraan yang } \\
\text { melintas dan membeli) }\end{array}$ \\
\hline Fasilitas & $\begin{array}{l}\text { F1 (tungku pengasapan, } \\
\text { listrik, air) }\end{array}$ \\
\hline Biaya & B1 (Bebas biaya parkir) \\
\hline
\end{tabular}

\section{HASIL DAN PEMBAHASAN}

Pedagang ikan asap yang berjualan di sekitar jalanan pantai Kenjeran terdiri dari laki - laki dan wanita dengan rentang usia 20 hingga 60 tahun. Pendidikan terakhir yang ditempuh oleh pedagang ikan asap yaitu 14\% tidak sekolah, 33\% SD, 38\% SMP, dan 14\% SMA. Pedagang ikan asap yang berjualan di jalan Pantai Kenjeran terbagi menjadi $19,05 \%$ berjualan di pinggir jalan, 47,61\% berjualan di depan rumah, dan 33,33\% sewa dengan rata - rata biaya sebesar Rp 554.286/bulan. Terdapat $28,6 \%$ pedagang ikan asap yang berjualan $\leq$ 5 tahun, 52,4 berjualan $\leq 10$ tahun, dan $19 \%$ berjualan lebih dari 10 tahun. Jenis ikan asap yang dijual oleh pedagang antara lain ikan mayung, pari, tengiri, keting, bandeng, dan kakap. 38,10\% dari pedagang ikan asap pernah menghuni Sentra Ikan Bulak (SIB) akan tetapi memilih berjualan lagi di sekitar jalan Pantai Kenjeran. Hal ini disebabkan oleh keadaan pembeli ikan asap di SIB yang sepi. Pembeli lebih memilih membeli di pedagang ikan asap yang ada di sekitar jalan.

Dari data yang telah didapat melalui kuesioner dilakukan uji validitas dan reliabilitas untuk mengukur keabsahan dan keandalan kuesioner. Hasil uji validitas dinyatakan valid karena $\mathrm{r}$ hitung > $\mathrm{r}$ tabel, dimana $r$ tabel dengan $n=21$ dan $\alpha=0,05$ 
bernilai 0,433. Sedangkan pada uji reliabilitas, didapatkan nilai Cronbach's Alpha sebesar 0,846. Suatu instrumen dikatakan reliabel jika Cronbach's Alpha mencapai 0,70 (Nawi, A.Tambi, et al., 2020).

Variabel yang digunakan untuk mengetahui faktor - faktor yang memengaruhi pemilihan lokasi usaha pedagang ikan asap di sekitar jalan Pantai Kenjeran terdiri dari aksesibilitas, visitabilitas, lalu lintas, lingkungan, fasilitas dan biaya. Variabel ini diuji dengan analisis faktor hingga didapatkan nilai KMO
(Kaiser-Mayer-Olkin) MSA (Measures of Sampling Adequancy). Dari hasil analisis, diketahui bahwa nilai KMO MSA (KaiserMayer-Olkin Measures of Sampling Adequancy) sebesar 0,663 > 0,50 dan nilai MSA pada setiap variabel $>0,50$ sehingga analisis faktor dapat dilanjutkan.

Berdasarkan hasil analisis data menunjukkan bahwa faktor - faktor yang memengaruhi pemilihan lokasi usaha pedagang ikan asap di sekitar jalan Pantai Kenjeran dapat dijelaskan oleh persentase dari masing - masing faktor dalam nilai Total Variance Explained.

Tabel 2. Total Variance Explained

\begin{tabular}{crrrrrr}
\hline \multirow{2}{*}{ Component } & \multicolumn{3}{c}{ Initial Eigenvalues } & \multicolumn{2}{c}{ Extraction Sums of Squared Loadings } \\
\cline { 2 - 6 } & Total & $\begin{array}{c}\text { \% of } \\
\text { variance }\end{array}$ & Cumulative \% & Total & \multicolumn{1}{c}{$\begin{array}{c}\text { \% of } \\
\text { variance }\end{array}$} & Cumulative \% \\
\hline $\mathbf{1}$ & 4,267 & 47,416 & 47,416 & 4,267 & 47,416 & 47,416 \\
\hline $\mathbf{2}$ & 1,256 & 13,953 & 61,369 & 1,256 & 13,953 & \\
\hline $\mathbf{3}$ &, 954 & 10,595 & 71,963 & & \\
\hline $\mathbf{4}$ &, 751 & 8,344 & 80,307 & & \\
\hline $\mathbf{5}$ &, 648 & 7,205 & 87,512 & & \\
\hline $\mathbf{6}$ &, 550 & 6,106 & 93,618 & & \\
\hline $\mathbf{7}$ &, 296 & 3,294 & 96,913 & & \\
\hline $\mathbf{8}$ &, 158 & 1,752 & 98,665 & & \\
\hline $\mathbf{9}$ &, 120 & 1,335 & 100,000 & & \\
\hline
\end{tabular}

Total Variance Explained menggambarkan jumlah faktor yang terbentuk. Hal ini dapat dilihat dari nilai eigenvalue diatas 1. Eigenvalue menunjukkan kepentingan relatif masing masing faktor dalam menghitung varians dari total faktor yang ada. Dari 9 faktor, terdapat 2 faktor yang terbentuk dengan nilai eigenvalue > 1 yaitu faktor 1 yang memiliki nilai eigenvalue sebesar 4,267 dengan nilai varians $47,416 \%$ dan faktor 2 yang memiliki nilai eigenvalue sebesar 1,256 dengan nilai varians $13,953 \%$. 
Tabel 3. Rotated Component Matrix

\begin{tabular}{lcc}
\hline \multicolumn{1}{c}{ Faktor } & \multicolumn{2}{c}{ Component } \\
\cline { 2 - 3 } & 1 & 2 \\
\hline $\begin{array}{l}\text { A1 (kemudahan keluar masuk } \\
\text { jalan raya) }\end{array}$ & 0,469 & $\mathbf{0 , 6 0 5}$ \\
\hline A2 (dilalui transportasi umum) & $\mathbf{0 , 5 3 8}$ & 0,212 \\
\hline A3 (mudah dijangkau) & $\mathbf{0 , 6 7 7}$ & 0,143 \\
\hline V1 (dekat dengan jalan raya) & $\mathbf{0 , 7 5 1}$ & 0,437 \\
\hline V2 (terdapat penanda) & $\mathbf{0 , 6 3 3}$ & 0,182 \\
\hline $\begin{array}{l}\text { LL1 (volume kendaraan yang } \\
\text { melintas) }\end{array}$ & 0,046 & $\mathbf{0 , 9 0 6}$ \\
\hline $\begin{array}{l}\text { LL2 (volume kendaraan yang } \\
\text { melintas dan membeli) }\end{array}$ & $\mathbf{0 , 6 4 6}$ & 0,514 \\
\hline F1 (kelengkapan fasilitas) & $\mathbf{0 , 7 5 4}$ & 0,365 \\
\hline B1 (bebas biaya parkir) & $\mathbf{0 , 7 9 9}$ & 0,302 \\
\hline
\end{tabular}

Berdasarkan tabel Rotated

Component Matrix, diketahui bahwa komponen faktor pertama terdiri dari dilalui transportasi umum, mudah dijangkau, dekat dengan jalan raya, terdapat penanda, volume kendaraan yang melintas dan membeli, kelengkapan fasilitas, dan bebas biaya parkir. Sedangkan pada faktor yang kedua terdiri dari kemudahan keluar dan masuk jalan raya dan volume kendaraan yang melintas.

Terdapat 2 cara dalam penamaan faktor baru, yaitu dari nama yang mampu mewakili komponen yang baru terbentuk atau melalui pendekatan surrogatte variabel (memilih variabel dengan nilai loading faktor tertinggi). Penelitian ini menggunakan pembentukan nama baru yang mewakili komponen pembentuknya. Hal ini dapat dilihat pada Tabel 4.
Tabel 4. Penamaan Faktor Baru

\begin{tabular}{|c|c|c|}
\hline $\begin{array}{l}\text { Nama } \\
\text { Faktor }\end{array}$ & Komponen Pembentuk & $\begin{array}{c}\text { Nilai } \\
\text { Varian } \\
\text { Faktor }\end{array}$ \\
\hline \multirow{7}{*}{$\begin{array}{l}\text { Akses } \\
\text { dan } \\
\text { fasilitas }\end{array}$} & $\begin{array}{l}\text { Dilalui } \\
\text { umum }\end{array}$ & \multirow[t]{7}{*}{$47,416 \%$} \\
\hline & Mudah dijangkau & \\
\hline & Dekat dengan jalan raya & \\
\hline & Terdapat penanda & \\
\hline & $\begin{array}{l}\text { Volume kendaraan yang } \\
\text { melintas dan membeli }\end{array}$ & \\
\hline & Kelengkapan fasilitas & \\
\hline & Bebas biaya parkir & \\
\hline \multirow[t]{2}{*}{$\begin{array}{l}\text { Lalu } \\
\text { lintas }\end{array}$} & $\begin{array}{ll}\text { Kemudahan } & \text { keluar } \\
\text { masuk jalan raya } & \end{array}$ & \multirow[t]{2}{*}{$13,953 \%$} \\
\hline & $\begin{array}{l}\text { Volume kendaraan yang } \\
\text { melintas }\end{array}$ & \\
\hline
\end{tabular}

Faktor pertama diberi nama akses dan fasilitas karena indikatornya yaitu dilalui transportasi umum, mudah dijangkau, dekat dengan jalan raya, dan volume kendaraan yang melintas dan membeli dapat mewakili aksesibilitas. Sedangkan indikator terdapat penanda, kelengkapan fasilitas, dan bebas biaya parkir dapat mewakili fasilitas yang dimiliki di lokasi usaha. faktor akses dan fasilitas merupakan faktor yang paling dominan karena memiliki nilai varian faktor tertinggi yaitu 47,416\%. Hal ini menjelaskan bahwa faktor akses dan fasilitas memengaruhi pemilihan lokasi usaha pedagang ikan asap di sekitar jalan Pantai Kenjeran sebesar 47,416\%. Hal ini sesuai dengan penelitian yang dilakukan oleh Ulaga, Sharma, and Krishnan (2002) bahwa akses pelanggan dan infrastruktur/fasilitas merupakan salah satu atribut dalam pemilihan lokasi. Menurut 
Mazzarol and Choo (2003), faktor kedekatan/mudah diakses merupakan faktor yang memengaruhi pemilihan lokasi pada industri kecil.

Akses dan fasilitas sangat memengaruhi pemilihan lokasi usaha pedagang ikan asap. Pedagang ikan asap memilih berjualan di sekitar jalan karena Sentra Ikan Bulak (SIB) sepi pembeli. Jika dibandingkan dengan pedagang ikan asap di sekitar jalan, pedagang ikan asap di Sentra Ikan Bulak (SIB) tidak mudah dijangkau karena berada dibagian dalam Sentra Ikan Bulak (SIB) sehingga pengunjung yang ingin membeli ataupun hanya melihat lihat harus masuk dulu ke dalam Sentra Ikan Bulak (SIB) dan harus membayar parkir sebesar Rp 2.000/motor dan Rp 5.000/mobil. Selain itu, kios pedagang ikan asap yang terletak di bagian belakang Sentra Ikan Bulak (SIB) mengakibatkan para pedagang ini tidak terlihat dari luar/jalan raya sehingga banyak orang yang melintas tidak mengetahui keberadaan para pedagang ini. Hal ini berbanding terbalik dengan kondisi pedagang ikan asap di sekitar jalan Pantai Kenjeran yang berjejer di dekat jalan raya sehingga sangat terlihat dan menjadi penanda sentra ikan asap.

\section{KESIMPULAN DAN SARAN}

Berdasarkan penelitian yang telah dilaksanakan, dapat disimpulkan dari
Alasan masih ada beberapa pedagang ikan asap yang bertahan di Sentra Ikan Bulak (SIB) karena sudah memiliki pelanggan tetap (langganan) dan bebas biaya sewa sehingga pedagang tidak khawatir ikan asapnya tidak laku karena Sentra Ikan Bulak (SIB) sepi pengunjung. Rata - rata ikan asap sudah habis terjual pada pukul 12.00 WIB.

Faktor yang kedua diberi nama lalu lintas karena terbentuk dari indikator kemudahan keluar masuk jalan raya dan volume kendaraan yang melintas sehingga dapat mengggambarkan keadaan lalu lintas di lokasi usaha. Faktor lalu lintas memiliki nilai varian faktor sebesar $13,953 \%$ yang menjelaskan bahwa faktor ini memengaruhi pemilihan lokasi usaha pedagang ikan asap di sekitar jalan Pantai Kenjeran sebesar $13,953 \%$. Lokasi usaha yang mudah untuk keluar dan masuk jalan raya akan memberikan kenyamanan bagi pedagang maupun pembeli. Selain itu banyaknya volume kendaraan/orang yang melintas dapat meningkatkan jumlah pembeli karena orang tersebut tertarik melihat para pedagang yang berjejer di sekitar jalan Pantai Kenjeran (pembeli spontan).

variabel aksesibilitas, visitabilitas, lalu lintas, fasilitas, dan biaya, terdapat 2 faktor yang memengaruhi pemilihan lokasi 
pedagang ikan asap di sekitar jalan Pantai Kenjeran, yang pertama adalah akses dan fasilitas dan yang kedua adalah lalu lintas. Faktor akses dan fasilitas menjadi faktor yang paling dominan dengan nilai varian faktor sebesar 47,416\%. Untuk meningkatkan minat pedagang ikan asap yang berjualan di sekitar jalan Pantai Kenjeran adar mau menempati SIB, maka Pemerintah Kota Surabaya harus meningkatkan aksesibilitas dan fasilitas di SIB seperti membebasan biaya parkir dan penataan ulang kios ikan asap di SIB agar dapat terlihat dari jalan.

\section{DAFTAR PUSTAKA}

Alcácer, Juan. 2006. "Location Choices Across the Value Chain: How Activity and Capability Influence Collocation Location Choices Across the Value Chain: How Activity and Capability Influence Collocation." Management Science 52 (10): 145771.

https://doi.org/10.1287/mnsc.1060.06 58.

Dinas Pertanian Kota Surabaya Bidang Perikanan. 2020. "Produksi Perikanan Tangkap 2020." Surabaya : DKPP.

Dubé, Jean, Cédric Brunelle, and Diègo Legros. 2016. "Location Theories and Business Location Decision : A MicroSpatial Investigation of a Nonmetropolitan Area in Canada." The Review of Regional Studies 46 (2): 143-70. https://doi.org/10.52324/001c.8039.

Etikan, Ilker, Sulaiman Abubakar Musa, and Rukayya Sunusi Alkassim. 2016.
"Comparison of Convenience Sampling and Purposive Sampling." American Journal of Theoretical and Applied Statistics 5 (1): 1-4. https://doi.org/10.11648/j.ajtas.20160 501.11 .

Haming, M. dan Mahmud Nurnajamuddin. 2011. "Manajemen Produksi Modern Operasi Manufaktur dan Jasa." Jakarta: Bumi Aksara.

Heizer dan Reinder. 2012. "Operations Management (Menejemen Operasi)." Jakarta: Salemba Empat.

In seok, Jo, Jo Gyu yeon, and Ahn Sang Bong. 2016. "외식 프랜차이즈 입지요건과 서비스 품질 요인이 고객만족에 미치는 영향 *." AsiaPacific Journal of Business Venturing and Entrepreneurship 11 (5): 77-90.

Mawardi, Amna. 2021. "Efektifitas Waktu Tunggu dan Lokasi Terhadap Kepuasan Pelanggan." E-QIEN Jurnal Ekonomi Dan Bisnis 8 (1): 13-18.

Mazzarol, Tim, and Stephen Choo. 2003. "A Study of the Factors Influencing the Operating Location Decisions of Small Firms A Study of the Factors Influencing the Operating Location Decisions of Small Firms." Property Management $21 \quad$ (2): 190. https://doi.org/10.1108/02637470310 478918.

Nanda, Yuli, and Fikriah. 2016. "FaktorFaktor yang Mempengaruhi Pemilihan Lokasi Pedagang Kaki Lima di Kota Banda Aceh." Jurnal Ilmiah Mahasiswa (JIM) 1 (1): 270-81.

Nawi, Farahiyah Akmal Mat, Abdul Malek A.Tambi, Muhammad Faizal Samat, and Wan Masnieza Wan Mustapha. 2020. "A Review on The Internal Consistency of a Scale : The Empirical Example of The Influence of Human 
Capital Investment On.” Asian People Journal 3 (1): 19-29. https://doi.org/10.37231/apj.2020.3.1. 121.

Sastrawan, I Wayan. 2015. "Analisis Faktor-Faktor yang Mempengaruhi Pemilihan Lokasi Usaha Pedagang Kaki Lima di Pantai Penimbangan Kecamatan Buleleng, Kabupaten Buleleng." Jurnal Pendidikan Ekonomi Undiksha 5 (1): 1-10.

Supranto, J. 2010. "Statistika." Jakarta: Erlangga.

Tjiptono, Fandy. 2015. "Strategi Pemasaran, Edisi 4." Yogyakarta : Andi Offset.
Ulaga, Wolfgang, Arun Sharma, and R Krishnan. 2002. "Plant Location and Place Marketing: Understanding the Process from the Business Customer' s Perspective." Industrial Marketing Management 31: 393-401.

Wahyudi, Nur, Efreda A. Lau, and Heriyanto. 2014. "Analisis FaktorFaktor Pemilihan Lokasi Usaha Terhadap Kesuksesan Usaha Jasa Mikro di Kecamatan Sungai Kunjang.” Ekonomia 3 (3): 136-43.

Williams, Brett, and Ted Brown. 2012. "Exploratory Factor Analysis : A FiveStep Guide for Novices." Australasian Journal of Paramedicine 8 (3): 1-13. 